\title{
Frentenegrinas: \\ notas de um capítulo da participação feminina na história da luta anti-racista no Brasil ${ }^{*}$
}

\author{
Petrônio Domingues**
}

\begin{abstract}
Resumo
$\mathrm{O}$ artigo procura investigar a questão da mulher negra em uma perspectiva histórica, recuperando a trajetória e participação desse estrato populacional na Frente Negra Brasileira (1931-1937), considerada a maior (e a mais importante) entidade anti-racista do país no período do pós-Abolição. A principal pergunta a ser respondida aqui se refere ao papel desempenhado pelas mulheres na Frente Negra Brasileira e no seu órgão informativo - jornal $A$ Voz da Raça.
\end{abstract}

Palauras-chave: Mulher Negra, Negro, Racismo, Relações Raciais.

\footnotetext{
* Recebido para publicação em agosto de 2005, aceito em março de 2006.

*** Professor da Universidade Estadual do Oeste do Paraná - Unioeste, CascavelPR.petronio@usp.br
}

cadernos pagu (28), janeiro-junho de 2007:345-374. 
Participação feminina na história da luta anti-racista no Brasil

Frentenegrinas:

Notes on a Chapter of Women's Participation in the History

of Anti-Racism

Abstract

This article investigates the black woman's question in historical perspective, following their path and participation in the Frente Negra Brasileira (1931-1937), considered to be the major of the anti-racist movements in the country after the abolition period. The central question focuses on the women's role in the Front and in its information organ, the newspaper A Voz da Raça.

Key Words: Black Women, Black People, Racism, Racial Relations. 
Petrônio Domingues

\section{Introdução}

A história da mulher negra no Brasil ainda não foi devidamente contada. Se a historiografia já se ocupou, razoavelmente, da temática da mulher negra na época da escravidão, o mesmo não se pode afirmar para a época do pósAbolição. Com a questão da resistência negra, o fenômeno se repete. Se já existem pesquisas que exploraram a participação da mulher negra nos movimentos de resistência no período da escravidão ${ }^{1}$, o mesmo não se pode dizer para o período do pósAbolição. Como a mulher negra participou da luta anti-racista nesse período? Trata-se de uma lacuna que precisa ser preenchida.

Já foram realizadas pesquisas sobre a instituição do movimento negro nas primeiras décadas do século $\mathrm{XX}^{2}$, mas geralmente não há uma preocupação de abordar a presença da mulher negra neste processo. Com a Frente Negra Brasileira (FNB) - considerada a maior (e mais importante) entidade anti-racista da história do país no pós-Abolição - o problema se reproduz. As pesquisas não costumam fazer justiça à participação da mulher negra na organização. ${ }^{3}$ Para o leitor desavisado, fica a impressão de que a FNB só era composta por homens ou só os homens desempenharam um papel de relevância nela $e$, por isso, merecem entrar para os anais da história.

Este artigo pretende contribuir para romper com a invisibilidade feminina em um dos capítulos da história do movimento negro, apresentando algumas notas da participação

\footnotetext{
${ }^{1}$ Para a história da mulher negra (cativa, forra ou livre) no período da escravidão e suas formas de resistência, ver Dias, 2003; Graham, 2005; Giacomini, 1988; Grinburg, 1994; Mott, 1979:7-9 e 1993; Mott, 1988; Paiva, 2001; Soares, 1996.

2 Ver Leite e Moreira, s/d; Fernandes, 1978; Moura, 1980; Silva, 1990; Cardoso, 1993; Andrews, 1998.

3 Ver Bicudo, 1945; Mitchell, 1977; Maués, 1997; Butler, 1998; Oliveira, 2002; Silva, 2003
} 
Participação feminina na história da luta anti-racista no Brasil

das mulheres na Frente Negra Brasileira (1931-1937). Eis as principais questões aqui examinadas: qual foi o papel das mulheres na Frente Negra Brasileira e no seu órgão informativo, o jornal A Voz da Raça? Como as "frentenegrinas" (termo como as mulheres da FNB eram chamadas) se engajaram na luta pela conquista da cidadania? Como elas eram representadas no jornal A Voz da Raça?

A FNB não foi criada da noite para o dia; ela foi resultado do acúmulo de experiência organizativa dos negros no pósAbolição. Artur Ramos observa que o "espírito associativo" do negro marcou sua trajetória no país. Desde a escravidão, esse segmento populacional desenvolveu diversas formas de organização coletiva. Até a Abolição, foram criados grupos ou associações de caráter religioso, cultural e socioeconômico representados por quilombos, confrarias, irmandades religiosas, caixas de empréstimos, etc. (Ramos, 1938).

No período do pós-Abolição (transição do século XIX para o $\mathrm{XX}$ ), os negros criaram diversas associações em São Paulo: grêmios recreativos, sociedades cívicas e beneficentes. A maioria delas possuía estatuto e era conduzida por um presidente, auxiliado por uma diretoria escolhida através de eleições. As associações negras mantinham uma ativa vida social, muitas delas se reuniam diariamente. A maioria tinha como eixo central de atuação garantir o lazer de seus afiliados, principalmente por meio dos bailes dançantes. As associações negras cumpriam, fundamentalmente, o papel de produtoras de uma identidade específica, de um "nós", negros, em oposição a "eles", brancos.

Algumas associações publicavam jornais e mantinham uma diretoria de "damas", como era o caso do O Kosmos e da Sociedade 15 de Novembro. Quatro delas eram formadas estritamente por mulheres, a Sociedade Brinco das Princezas, o Grêmio Recreativo Rainha Paulista, o Grêmio Recreativo 8 de Abril e o Grupo das que não ligam importância. De 1897 a 1930, existiram 85 associações negras funcionando na cidade de São Paulo - 25 dançantes, 9 beneficentes, 4 cívicas, 14 esportivas, 
21 grêmios recreativos, dramáticos e literários, além de 12 cordões carnavalescos (Domingues, 2004:329). Esses números são indicadores da capacidade de mobilização da comunidade negra na época.

Praticamente em todo período da Primeira República (18891930) há vestígios da existência de grupos negros funcionando em São Paulo, porém é a partir do início do século XX que ocorreu sua expansão. Dentre os diversos grupos que surgiram até 1930, o Centro Cívico Palmares foi a mais importante, quer pela proposta de elevação política, moral e cultural, quer pelo grau de organização e capacidade de penetração na comunidade negra.

Nesta época, apareceu em São Paulo o que se denominou "imprensa negra": jornais publicados por negros e voltados para suas questões. Um importante jornal da imprensa negra foi o Progresso, fundado em 1928, quando os negros decidiram comemorar o centenário de nascimento de Luís Gama, inaugurando uma herma no Largo do Arouche. Dirigido por Lino Guedes e Argentino Celso Wanderley, o Progresso tinha como metas "exaltar e valorizar o negro e voltar suas reivindicações contra o preconceito de cor" (Ferrara, 1986:197).

O principal jornal da imprensa negra durante o período da Primeira República foi O Clarim da Alvorada, fundado em 1924 por José Correia Leite e Jaime de Aguiar. Ele surgiu como um órgão "literário, noticioso e humorístico". No entanto, no final da década de 1920, o subtítulo do jornal já sinalizava que o órgão não se debruçaria apenas sobre temas "literário, noticioso $e$ humorístico", mas se tornou um "Legítimo órgão da mocidade negra de São Paulo. Pelo interesse dos homens pretos. Noticioso, literário e de combate", ou seja, um instrumento de luta contra a discriminação racial (O Clarim da Alvorada, 09/06/1929).

Uma característica da imprensa negra foi o predomínio absoluto dos homens. No levantamento realizado entre 1907 e 1937, Regina Pinto verificou que apenas 15 dos 244 colaboradores eram mulheres. A mulher também esteve ausente dos cargos de chefia: "apenas uma mulher integrou o corpo editorial do jornal $O$ 
Participação feminina na história da luta anti-racista no Brasil

Clarim em 1935, exercendo a função de redatora" (Pinto, 1993:64). Um editorial do jornal Getulino definia o papel social da mulher: "a mulher foi criada para mãe, para doce companheira do homem, e nesse sentido, a sua constituição física e moral é para o completo desenvolvimento dessa missão" (Getulino, 02/09/1923:1). O machismo ficava mais explícito em O Clarim da Alvorada, na medida em que se propagava uma concepção de família de modelo patriarcal:

A grande obra da ação negra no Brasil deve começar pela família pois que é ela a célula-mãe de toda a sociedade civil. E a família é a união do varão $e$ a esposa com seus filhos, debaixo do governo do varão (O Clarim da Alvorada, 13/05/1927:3).

A experiência histórica das associações negras do pósAbolição, especialmente do Centro Cívico Palmares, e da imprensa negra, particularmente $\mathrm{O}$ Clarim da Alvorada e o Progresso, impulsionou o movimento que redundou na fundação da FNB no início da década de 1930.

\section{Uma breve história da Frente Negra Brasileira}

A chegada de Getúlio Vargas ao poder, com o golpe de Estado de 3 de Outubro de 1930, abriu uma conjuntura de polarização política no Brasil. Contudo, tanto as organizações políticas de base popular quanto os partidos da elite não incluíam em seus programas a luta a favor da população negra. Abandonados pelo sistema político tradicional e acumulando a experiência de décadas em suas associações, os negros paulistas criaram a Frente Negra Brasileira (FNB) no salão das Classes Laboriosas, no dia 16 de setembro de 1931 - 43 anos após a extinção da escravidão no Brasil. Quase um mês depois, em assembléia realizada no mesmo local de fundação, foi lido e aprovado o Estatuto, que estabelecia: 
Art. $1^{\circ}$ - Fica fundada nesta cidade de São Paulo, para se irradiar por todo o Brasil, a "FRENTE NEGRA BRASILEIRA", união política e social da Gente Negra Nacional, para afirmação dos direitos históricos da mesma, em virtude da sua atividade material $e$ moral no passado e para reivindicação de seus direitos sociais e políticos, atuais, na Comunhão Brasileira.

Art. $2^{\circ}$ - Podem pertencer à "FRENTE NEGRA BRASILEIRA" todos os membros da Gente Negra Brasileira de ambos os sexos, uma vez capazes, segundo a lei básica nacional.

Art. $3^{\circ}$ - A "FRENTE NEGRA BRASILEIRA", como força social, visa a elevação moral, intelectual, artística, técnica, profissional e física; assistência, proteção e defesa social, jurídica, econômica e do trabalho da Gente Negra.

Inciso Único - Para execução do art. $3^{\circ}$, criará cooperativas econômicas, escolas técnicas e de ciências e artes, e campos de esportes dentro de uma finalidade rigorosamente brasileira.

Art. $4^{\circ}$ - Como força política organizada, a "FRENTE NEGRA BRASILEIRA", para mais perfeitamente alcançar os seus fins sociais, pleiteará, dentro da ordem legal instituída no Brasil, os cargos eletivos de representação da Gente Negra Brasileira, efetivando a sua ação político-social em sentido rigorosamente brasileiro.

Art. $5^{\circ}$ - Todos os meios legais de organização necessários a consecução dos fins da "FRENTE NEGRA BRASILEIRA" serão distribuídos em tantos departamentos de ação quantos forem precisos, constando de regulamento especial (Diário Oficial do Estado de São Paulo, 04/11/1931:12).

A FNB assumiu um projeto anti-racista que tinha como principal ideal a integração do negro, como cidadão brasileiro, à ordem social vigente. A mobilização em massa dos negros na luta contra o "preconceito de cor" assustou alguns setores das elites. Por isso, a FNB foi acusada, várias vezes, de insuflar o conflito ou ódio racial no Brasil. 
Participação feminina na história da luta anti-racista no Brasil

A organização cresceu rapidamente. Pelas estimativas de um de seus dirigentes, no seu auge, a FNB reuniu de 25 a 30.000 filiados (Domingues, 2004a:16), somando os efetivos de todas as "delegações", as quais funcionavam como filiais da sede na capital paulista. Em 1936, a entidade contava com mais de 60 delegações distribuídas no interior de São Paulo e em outros Estados - Rio de Janeiro, Minas Gerais, Espírito Santo -, além de manter um certo vínculo com organizações de mesmo nome no Rio Grande do Sul, Bahia e Pernambuco. Do ponto de vista social, a FNB reunia em seus quadros a grande "massa de cor" (desempregados, trabalhadores de cargos subalternos e serviços braçais) $e$, em menor escala, parte de segmentos das camadas médias negras (funcionários de escritórios e profissionais liberais). Estes últimos assumiam os cargos de direção da organização (Andrews, 1998:233).

No decorrer de sua trajetória (setembro de 1931 a dezembro de 1937), a FNB foi presidida por Arlindo Veiga dos Santos, que ocupou o cargo até pedir afastamento, em junho de 1934. Com sua saída, assumiu a presidência Justiniano Costa, que nesta época exercia a função de tesoureiro. A entidade criou uma série de símbolos diacríticos (carteira de identidade com foto $e$ dados pessoais do filiado, bandeira e hino), a fim de garantir visibilidade para suas ações, gerar uma identidade específica para seus associados e, ao mesmo tempo, adquirir credibilidade no seio da população negra e na sociedade em geral. Todo trabalho da militância era voluntário. A principal fonte de recurso da entidade era proveniente da mensalidade dos associados.

No casarão da Rua da Liberdade $\mathrm{n}^{\circ} 196$, onde sua sede estava localizada, a FNB mantinha um bar, salão de beleza com barbeiro e cabeleireiro, salão de jogos, oficina de costura, posto de alistamento eleitoral e uma caixa beneficente que prestava auxílio médico, hospitalar, farmacêutico e funerário aos associados. A FNB era prestigiada entre os negros de um modo geral, que "a procuravam para resolver problemas de moradia, de emprego" (Pinto, 1993:91). 
Para organizar sua atuação em diversas áreas, a entidade dividia-se em departamentos, como o de Instrução ou de Cultura, Jurídico-Social, Médico, Artes e Ofícios, Doutrinário, Dramático, Musical, Esportivo e Imprensa. Este último era responsável pela publicação do jornal da entidade - A Voz da Raça -, órgão oficial de divulgação dos ideais da entidade. Com tiragem de 1.000 a 5.000 exemplares, o jornal era mantido com recursos da entidade $e$ dos anunciantes e chegou a ser lido no continente africano e nos Estados Unidos.

A Voz da Raça voltou sua atenção, quase que exclusivamente, para um público específico - a população negra -, noticiando as questões peculiares da vida desta população. $\mathrm{O}$ aparecimento do jornal imprimiu um dinamismo maior à FNB. Para Roger Bastide, A Voz da Raça marca a transição para uma nova fase da imprensa negra, com a "passagem da reivindicação jornalística à reivindicação política" (Bastide, 1951:54). José Carlos G. da Silva vai mais longe, argumentando que a publicação do jornal inaugurou uma nova fase na vida da FNB:

as discussões até então quase privadas, limitadas a um pequeno grupo, tornaram-se públicas. O modelo de sociedade corporativa defendido pela Frente Negra, em um contexto altamente polarizado ideologicamente, tornou-se de domínio publico, gerando profundas polêmicas, discussões e rupturas, até mesmo no interior da própria entidade (Silva, 1990:135).

A Voz da Raça mantinha representantes em várias cidades do interior de São Paulo e em outros Estados - Rio de Janeiro, Minas Gerais, Espírito Santo e Rio Grande do Sul -, que realizavam o trabalho de divulgação e, ao mesmo tempo, enviavam notícias das "delegações" (filiais) para serem publicadas. Um aspecto interessante na linguagem do jornal foi o emprego de sujeitos no masculino e no feminino. Para se referir a ambos os sexos, usava-se com certa freqüência as conjugações 
Participação feminina na história da luta anti-racista no Brasil

"frentenegrinos e frentenegrinas", "meus irmãos e minhas irmãs negras", "negros e negras", "irmãos e irmãs da raça", "senhores e senhoritas", "leitores e leitoras", "moços e moças", "meninos e meninas".

A FNB foi a entidade do movimento negro que mais adquiriu força política nas primeiras décadas do século $\mathrm{XX}$, chegando a ser recebida em audiência pelo presidente da República, Getúlio Vargas, e pelo então governador do Estado de São Paulo, Armando de Salles Oliveira. A entidade auferiu algumas conquistas concretas no campo dos direitos civis, como eliminar a prática de proibir o ingresso de negros nos rinques de patinação e na Guarda Civil de São Paulo.

A FNB recebeu a visita de outras entidades do movimento social, como a Associação Cívica Feminina (A Voz da Raça, 12/1936:4). Em 1936, a entidade transformou-se em partido político e pretendia participar das próximas eleições. Do ponto de vista ideológico, defendia um projeto nacionalista, de viés autoritário. Arlindo Veiga dos Santos - o primeiro presidente da FNB - era radicalmente contrário à democracia e constantemente fazia apologia do fascismo europeu. Em 1937, com a instauração da ditadura do Estado Novo, a FNB foi extinta, assim como todos os partidos políticos. O fechamento da entidade causou uma sensação de frustração no meio negro em São Paulo.

\section{A mulher frentenegrina}

No seu livro clássico, A integração do negro na sociedade de classes, Florestan Fernandes descreveu a situação da mulher negra em São Paulo entre o final do século XIX e as primeiras décadas do século XX. Com o fim da escravidão, os homens negros foram excluídos do mercado de trabalho formal (ou incluídos marginalmente). Nesse contexto, o estrato feminino da população de "cor" teve, "em bloco, condições favoráveis de transição mais ou menos estável para o novo estilo de vida" (Fernandes, 1978:66). $\mathrm{Na}$ verdade, as mulheres negras não assumiam ocupações ideais 
ou compensadoras; elas tinham que se contentar com os empregos de domésticas, principalmente junto às "famílias tradicionais". Submetidas a um regime de exploração, as mulheres negras ainda tinham que cuidar dos filhos, manter o cônjuge (ou amásio), comprar os mantimentos, pagar o aluguel, enfim, arcar com as despesas domésticas. Nas palavras de Fernandes:

A mulher negra avulta, nesse período, (...) como a artífice da sobrevivência dos filhos e até dos maridos ou "companheiros". Sem a sua cooperação e suas possibilidades de ganho, fornecidas pelos empregos domésticos, boa parte da "população de cor" teria sucumbido ou refluído para outras áreas. Heroína muda e paciente, mais não podia fazer senão resguardar os frutos de suas entranhas: manter com vida aqueles a quem dera a vida! Desamparada, incompreendida e detratada, travou quase sozinha a dura batalha pelo direito de ser mãe (...). Nos piores contratempos, ela era o "pão" e o "espírito", consolava, fornecia o calor do carinho e a luz da esperança. Ninguém pode olhar para essa fase do nosso passado, sem enternecer-se diante da imensa grandeza humana das humildes "domésticas de cor", agentes a um tempo da propagação e da salvação do seu povo (Id. ib.:211).

Das jovens "negras" $e$ "mulatas" que viviam nos porões $e$ cortiços em estado de "promiscuidade", a quase totalidade "se infelicitava" fora de qualquer compromisso de noivado ou perspectivas de casamento. Vários informantes consultados por Fernandes indicaram que "as mães solteiras trabalhavam onde podiam, e quando não encontravam serviço, tinham de recorrer à mendicância e à prostituição ocasional" (Id. ib.:45). ${ }^{4}$ Portanto, a

4 Florestan Fernandes propala a versão de que a população negra vivia em estado de "anomia" em São Paulo nas primeiras décadas do século XX. Essa versão, porém, precisa ser problematizada. Fernandes cometeu algumas incúrias no uso das fontes de sua pesquisa. Uma delas foi aceitar, sem crítica, a autorepresentação de seus entrevistados e os preconceitos destes com relação à vida "desregrada" dos negros pobres. O discurso dos entrevistados não deve ser 
Participação feminina na história da luta anti-racista no Brasil

situação das mulheres negras nas primeiras décadas do século XX não era nada animadora. Ainda recaía sobre elas uma série de estereótipos negativos, como lasciva, volúvel, mulher à-toa, prostituta.

Em 1934, um dos principais dirigentes da Frente Negra Pelotense, Miguel Barros, participou do I Congresso AfroBrasileiro, organizado por Gilberto Freyre no Recife. Lá, ele fez um discurso de denúncia da discriminação racial no Rio Grande do Sul e, em determinado momento, relatou a situação da mulher negra:

A mulher é a ama, doméstica, costureira. Atualmente onde a mulher pode exercer sua atividade, é no funcionalismo, no professorado. Muitas etíopes, que se diplomam educadoras, lutam para conseguir lecionar e tem que o fazer particularmente, na impossibilidade de trabalhar para o Estado. A maioria desiste, vendo os exemplos dolorosos e vão para a costura, condição máxima, que pode desejar a mulher que possui os "considerados" característicos da descendência africana (Barros, 1988:271).

Em função do quadro descrito por Florestan Fernandes e Miguel Barros, a FNB desenvolveu uma preocupação especial com a mulher negra, ao menos foi isso que Arlindo Veiga dos Santos revelou em entrevista concedida para o jornal Folha da Noite em 1931:

Encheriam páginas trágicas as injustiças que há sofrido a Mulher Negra no Brasil [...]. A Mulher Negra eis um campo que deve fazer sentir profunda a ação dos que alistam na F.N.B. (homens e mulheres) (Folha da Noite, 22/12/1931:3).

tomado, ao pé da letra, como um registro da "realidade empírica", mas como algo que provavelmente reflete a sua posição de negros das camadas médias ou em ascensão social. Há uma bibliografia que desmonta a tese da "anomia" do negro no pós-abolição. Ver, entre outros, Andrews, 1998. 
Não era apenas Veiga dos Santos que demonstrava sensibilidade para discutir a situação da "mulher negra"; a FNB marcou reuniões específicas para tratar da questão.

Realiza-se hoje [divulgava a Folha da Manhã], "no salão n ${ }^{\circ}$ 16 da "Frente Negra Brasileira", a rua Liberdade, 196, uma reunião especial, dedicada ao elemento feminino, iniciando às 18 horas em ponto (Folha da Manhã, 27/03/1932:5).

Marcelino Félix (2001) faz alusão ao Departamento de Colocações Domésticas na FNB, que funcionava como uma espécie de agência de emprego. Seu objetivo era conseguir serviços domésticos - cozinheira, passadeira, copeira e lavadeira para as frentenegrinas. Fernandes argumenta que, em virtude das frentenegrinas terem adquirido consciência de seus direitos, muitas patroas passaram a evitá-las. Em compensação, outras lhes davam preferência, pois "sabiam que podiam confiar nelas, que era gente direita" (Fernandes, 1978:55). A Frente Negra da Bahia tinha como uma de suas metas criar uma nova imagem para a mulher negra, "daí a institucionalização de um quadro social feminino". Em entrevista concedida à imprensa local, dizia-se: "devemos mesmo trabalhar pela formação da elite da mulher negra" (apud Bacelar, 1996:76).

No que diz respeito à militância, Francisco Lucrécio declara que a mulher negra assumia uma posição de eminência nas lides a favor da população de "cor" na época, "de forma que na Frente [Negra] a maior parte eram mulheres. Era um contingente muito grande, eram elas que faziam todo movimento" (apud Barbosa, 1998:38). Desconsiderando os exageros desse antigo dirigente frentenegrino, coligiram-se alguns dados interessantes. $\mathrm{Na}$ delegação da FNB de Guaxupé/MG, 33 das 72 primeiras afiliações foram de mulheres (A Voz da Raça, 29/04/1933:2). Em certas delegações do interior e de outros Estados existiam o "núcleo de senhoras" (Id., 03/02/1934:2; 29/12/1934:2) ou "Diretoria Feminina" (Id., 10/06/1933:2), dirigido por e para as mulheres negras. Em 29 
Participação feminina na história da luta anti-racista no Brasil

de dezembro de 1934, o jornal A Voz da Raça noticiava a solenidade de posse da "Diretoria das Senhoras" da delegação de Passos/MG:

Na noite de nove do andante teve lugar a solene posse da diretoria das senhoras. Presidiu o ato o sr. João Candido dos Santos, que proferiu eloqüente discurso, enaltecendo o valor da mulher negra em todos os momentos históricos do Brasil.

A diretoria ficou composta das seguintes senhoras $e$ senhorinhas: d. Maria das Dores Rizolia, presidente; d. Joaquina Rosa Machado, vice-presidente; senhorinha Valéria Curvello Machado, secretaria; d. Sebastiana Caetano Machado, tesoureira.

Durante a solenidade houve diversos discursos $e$ declamações por diversas frentenegrinas. Para finalizar a sra. d. Maria Rizolia, em ardoroso improviso, agradeceu ao sr. delegado da F.N.B. por the ter conferido o cargo da diretoria feminina, dizendo que estava disposta a trabalhar com afinco pela grandeza da raça negra (Id., 29/12/1934:2).

No entanto, uma avaliação mais rigorosa da FNB central aponta que as mulheres eram subalternizadas na entidade $e$ alijadas dos cargos das instâncias decisórias, os quais eram monopolizados pelos homens. Nenhuma das frentenegrinas, por exemplo, compôs o "Grande Conselho" (instância máxima da FNB), provavelmente, porque prevalecia a concepção de que o papel social reservado "às meninas e moças" era o de "futuras esposas e mães", como prescrevia Arlindo Veiga dos Santos. ${ }^{5}$ Acreditava-se que as divisões de gênero no casamento deviam ser bem demarcadas. Ao escrever no jornal da entidade, o frentenegrino Benedito V. Costa definia:

${ }^{5}$ Folha da Noite, 22/12/1931:3. Talvez, em função disso, a maioria dos pais das famílias negras achava que as filhas "não precisavam estudar" (Fernandes, 1978:221). 
O esposo dá o pão e o conforto; a esposa, Deusa do lar, dá o beijo que encoraja e o carinho que revigora. [Em seguida, aconselhava que a mulher fosse] sempre fiel, dócil e carinhosa [para seu] esposo e defensor, [que] dará conforto e agasalho em seu terno coração (A Voz da Raça, 07/1936:3).

Em sintonia com a concepção dominante de gênero da época, Benedito Costa preconizava que o homem devia ser forte, provedor da família e ocupante do espaço público; em contrapartida, a mulher devia ser frágil, carinhosa e ficar confinada no espaço privado do lar, provavelmente cuidando da prole e das tarefas domésticas. Com discurso análogo, os dirigentes da Frente Negra Pelotense (FNP) postulavam que a mulher negra

deveria ficar em casa, cuidando dos filhos, enquanto o marido saía para o trabalho. [Devia ser] ela a encarregada de dar educação para as crianças negras, encaminhá-las para um futuro melhor da "raça", definido pela FNP como só sendo possível via educação (Santos, 2003:173).

De toda sorte, é plausível afirmar que as mulheres negras se dedicavam ativamente à FNB.

A reunião de ontem [da FNB], [noticiou o Diário de São Paulo], caracterizou-se pelo extraordinário comparecimento do elemento feminino. Cerca de 200 sócias estiveram presentes, tendo algumas delas tomado parte ativa nos debates travados (Diário de São Paulo, 19/01/1932:6).

As frentenegrinas até conquistaram a "Sala Feminina" (Id., 23/11/1935:1), um espaço na sede para tratar de suas questões. Dois eram os organismos internos que tinham um recorte de gênero: as Rosas Negras e a Cruzada Feminina. Mas não se pode superestimar os fatos: as mulheres negras ocupavam um papel tido como periférico na FNB. Os dois organismos que lhes eram 
Participação feminina na história da luta anti-racista no Brasil

destinados realizavam, apenas, atividades que os homens consideravam de menor importância: as recreativas $e$ as de assistência social.

\section{As Rosas Negras}

O primeiro agrupamento feminino da FNB - As Rosas Negras - era uma comissão (ou departamento) de mulheres que se vestiam de branco, usavam luvas e ostentavam uma rosa preta no peito, daí o nome Rosas Negras. Presidida por Benedita Costa, a comissão era responsável pela organização de saraus e festivais "litero-dramáticos e dançantes". Esses eventos serviam para aumentar a coesão do grupo. Ruth C. L. Cardoso propugna que não são apenas as reivindicações políticas que unificam os participantes de um movimento. A união, na ótica da autora, é uma "virtude em si mesma" e, para mantê-la, tanto se usa de atividades políticas quanto lúdicas (Cardoso, 1983:235). É neste contexto que devem ser concebidos os festivais promovidos pela FNB. Eles aconteciam mensalmente, com uma extensa programação: era de praxe abri-los com a apresentação de números musicais ou com as encenações teatrais (incluindo a declamação de poesias). Na parte final, realizava-se o baile dançante, até o amanhecer. A programação era divulgada no jornal da entidade:

Número de canto por alguns amadores do Corpo Cênico da FNB; apresentação do drama em um ato intitulado "O Escravo"; declamação e canto por alguns elementos do Corpo Cênico; depois de 60 minutos de representação o colossal Jaz Esmero dará início as marcações das contradanças, para só terminar as 4 da manhã (Id., 06/01/1934:3).

Canto da Gente Negra Brasileira, em seguida a declamação da poesia 13 de maio; apresentação do Corpo Cênico com a peça $O$ Vagabundo. Terminando a noitada com a 
retumbante e esplendorosa soirée dançante, abrilhantada pelo magnífico Jaz Jacaré (Id., 14/04/1934:3).

Além do "Jaz Esmero" e do "Jaz Jacaré", havia os grupos do Jazz "Mariano", "Ernesto", "Bandeirante", "Siqueira", "JazBande", "do Ademar", entre outros. Os estilos musicais mais tocados eram o "tango argentino", a "valsa" e o "fox-trot". Os festivais não aconteciam na sede da FNB e sim no salão da Liga Lombarda, da colônia italiana, no largo São Paulo; o salão da entidade não comportava a quantidade de pessoas que apareciam por lá. Os ingressos eram vendidos com antecedência na redação do jornal $A$ Voz da Raça ou na sede da FNB. Esta, aliás, vangloriava-se de que os festivais eram regidos por um ambiente familiar: "o que mais nos entusiasma é ver as senhorinhas acompanhadas de suas famílias", por isso seria "dessas festas que os elementos da raça negra devem freqüentar" (Id., 23/11/1935:3). Uma curiosidade era de que o momento dançante, dos bailes, era sempre relegado para a última parte da programação. Tal opção não era fortuita. Antes do momento recreativo, o frentenegrino tinha que assistir a sessões de peças teatrais e recitais de poesias que emitiam mensagens educativas.

Contudo, não se utilizava o termo baile para designar a última parte da programação dos festivais. Buscava-se evitar

qualquer vinculação destes momentos com certos bailes que a FNB tanto recriminava. Para referir-se a estes momentos organizados pelas Rosas Negras, os termos utilizados eram sarau dançante, contradança, $e$ até nomes meio afrancesados do tipo soirée dançante (Felix, 2001:s/p).

Ao promover bailes dançantes, a FNB incorria numa prática comum das associações recreativas negras de São Paulo na época. Mas não se pode confundir a proposta da FNB com a das outras associações. Naquela entidade, os bailes funcionavam como chamariz para os festivais que, além de proporcionar entretenimento, tinham um sentido doutrinário. 
Participação feminina na história da luta anti-racista no Brasil

\section{A Cruzada Feminina}

O segundo agrupamento do "movimento feminino" da FNB foi a Cruzada Feminina, uma comissão de mulheres cujas atribuições foram definidas em matéria publicada pelo jornal da entidade:

$1^{\circ}$ - Durante 12 meses consecutivos perseverar em trabalhos beneficientes e auxiliar o quanto possível no orçamento de provimento de material escolar para os cursos de formação social e preliminares diurno e noturno.

$2^{\circ}$ - Organizar as biografias dos fundadores da F.N. Brasileira e se possível, a galeria dos antepassados heróicos (ao menos com 20 retratos) para a inauguração no próximo 13 de Maio.

$3^{\circ}$ - Aumentar o número de assinantes d'A Voz da Raça (Id., 29/06/1935:3).

A Cruzada Feminina também contribuía nos preparativos do natal das crianças frentenegrinas, organizando a festa $e$ distribuindo os presentes. Porém, o objetivo central dessa comissão era fortalecer o campo educacional e cultural da FNB. Nela, Jersen de Paula Barbosa era a chefe, Francisca de Andrade a sub-chefe, Celina Veiga a secretária e Aracy de Oliveira, a tesoureira. Além delas, muitas frentenegrinas (cerca de dezoito mulheres e dois homens) se engajaram nos trabalhos da comissão.

A Cruzada Feminina procurou dotar a escola "diurna $e$ noturna" da FNB de uma melhor infra-estrutura e, ao mesmo tempo, garantir o pleno êxito dos alunos. Como estes eram carentes, ela adotou a política de oferecer gratuitamente material didático, uniforme e assistência odontológica. Para arcar com as despesas, a Cruzada Feminina realizava várias campanhas de arrecadação de fundos junto aos associados, por intermédio, principalmente, da venda de bilhetes de uma rifa cujo sorteio ocorria semanalmente pela Loteria Federal. Os bilhetes eram 
vendidos até ao preço máximo de $\$ 500$ (quinhentos réis) por um grupo de moças e a distribuição dos prêmios acontecia nas domingueiras. Os prêmios consistiam em prendas doadas pelos próprios associados.

Às vezes, as mulheres negras se destacavam nos eventos públicos promovidos pela FNB. Nas comemorações do 13 de Maio, elas participavam não só como coadjuvantes, mas também exercendo papel de certo relevo, como o de oradoras. Nas comemorações de 1933, discursaram diante do túmulo dos abolicionistas: Arlindo Veiga dos Santos, Pedro Paulo Barbosa e as frentenegrinas Silvia de Oliveira, Benedita Costa e Sebastiana Vieira. Quando esta última discursou, até os "corações mais duros" não resistiram "aos embates das suas palavras, que lhes foram ferir os sentimentos próprios, provados com as lágrimas que aflorara em todos os olhos" (Id., 20/05/1933:2). Porém, a mais prestigiada das oradoras era Benedita Costa Paranhos (Id., 11/1937:4).

Tendo em vista a valorização estética da mulher negra, a delegação da FNB de Jundiaí, em parceria com o Clube Recreativo 28 de Setembro, organizou o concurso Rainha Negra de Jundiaí, dentro das comemorações do 13 de Maio de 1934. A vencedora foi a "graciosa senhorinha" Zeferina Apolinário (Id., 26/05/1934:1). Em 1936, a delegação da FNB de Mococa organizou um concurso similar para se escolher a "Rainha das pessoas de cor". A vencedora foi Sebastiana Lima. Durante os festejos do 13 de Maio no teatro daquela cidade, ela foi coroada, recebendo a "faixa simbólica entre manifestações de entusiasmo e aplausos gerais" (Gazeta de Mococa, 17/05/1936).

\section{A frentenegrina no jornal $A$ Voz da Raça}

A FNB buscou emoldurar o negro num código de comportamento social e moral rigoroso. Arlindo Alves Soares diagnosticava que "grande parcela de negros" que compunham a população brasileira eram "incivilizados" (A Voz da Raça, 
Participação feminina na história da luta anti-racista no Brasil

17/03/1934:5), por isso, era necessário incorporar o que foi denominado de "código de civilidade". A entidade veiculou valores éticos, morais, culturais e ensinamentos de como o negro devia se comportar socialmente, tanto na esfera pública quanto na privada. O jornal A Voz da Raça publicava "o que nós os pretos devemos saber". As regras de etiqueta eram variadas e a mulher negra recebia uma atenção especial. Em nota, Noemia de Campos prescrevia:

Minhas irmãs negras; nós, antes de usarmos, boina, sapatos sem meia, blusa sem mangas e brincos argolão, devemos primeiramente consultar com as nossas costureiras ou pessoas amigas, para ver-se nos fica bem, para não sermos vítimas do riso dos transeuntes e vergonha das nossas irmãs que sabem trajar-se bem (Id., 30/09/1933:3).

A mesma Noemia de Campos, meses depois, voltava a patrulhar o comportamento das "irmãs de cor":

Há tempos uma revista desta paulicéia noticiara que as moças para tornarem-se mais chiques, precisariam usar sapatos sem meias; porém houve muitos protestos, das moças escrupulosas, contra essa ridícula moda, para que ela não fosse avante, mas mesmo assim, não sei porque algumas de nossas patrícias aparecem pelas ruas do centro, com sapatos sem meias, pensando, talvez que estão acompanhando a moda.

Minhas irmãs de cor. Observando como somos, nessas ocasiões, alvejados pelas críticas que aliás achoa-as, simplesmente, justas, em relação a esse pedantismo, forçame a assinalar aqui os meus protestos contra essa moda indecente.

Sejamos imitadoras de tudo quanto é bom e belo, mas das cousas que não afete a nossa dignidade (Id., 06/01/1934:4). 
O negro tinha que se preocupar em se vestir nos padrões vigentes da considerada boa aparência. Segundo o jornal A Voz da Raça, a FNB conscientizou a "mocidade negra" de que ela "andava inferior aos brancos no trajar", por isso, devia se capacitar nas "aparências exteriores" (Id., 04/1936:1). Também em função da ação educativa da FNB, as mulheres negras teriam passado a ser tão altivas e modernas quanto as brancas:

Rara era em S. Paulo, p. ex., a negrinha que ousasse usar chapéu, de medo das chufas dos brancos (e especialmente das brancas!). Hoje são legião as que usam esta indumentária que nada é em si mesma, porém define uma atitude social (Id. ib.)

Com efeito, o jornal da entidade, A Voz da Raça, timidamente se enveredou por discutir os problemas que atingiam a mulher negra. Talvez, porque a participação das frentenegrinas em sua linha editorial foi quase nula. Elas dificilmente escreviam artigos. E, quando escreviam, não apresentavam um recorte de gênero para a questão racial. Por exemplo, ao publicar o artigo "A luta de uma raça", Maria de Lourdes Rosário encetava: "Muito temos de lutar. Não arrefecemos. Prossigamos com ardor. A luta de uma raça que a quase dois séculos se iniciou" (Id., 15/07/1933:1). Maria de Lourdes Rosário foi a mulher que mais escreveu no jornal. Quando este comemorou seu primeiro aniversário, ela o homenageou com uma "Saudação à $A$ Voz da Raça":

Transcorrendo o seu natalício, como sua sincera admiradora, não poderia deixar de render-lhe as minhas singelas, mas fiéis homenagens tanto mais que esse órgão tem sido tão esforçadamente o porta voz (como o indica sua própria epígrafe) da gente negra brasileira, porém, da gente negra brasileira que de bom grado e patrioticamente tem sabido acolher o que é genuinamente brasileiro, genuinamente nosso, do negro, por assim dizer, e 
Participação feminina na história da luta anti-racista no Brasil

sobretudo, o que é, como ao nosso jornal digno pelas suas altas finalidades (Id., 17/03/1934:2).

Celina Veiga foi uma exceção. Em prédica, ela procurou combinar a questão racial e de gênero, encorajando as mulheres negras a partirem para a competição com as mulheres brancas:

A mulher negra precisa hoje em dia enfrentar a mulher branca; para isso, temos as armas necessárias de combate, são as seguintes: tenhamos moralidade, amor aos nossos negrinhos; fazendo-lhes ver os deveres para com a Pátria; ilustrando a inteligência $e$ o aperfeiçoamento das artes $e$ ofícios, para as quais sentimos vocação, e, principalmente, concorrendo em tudo e por tudo com a mulher branca, pondo a nossa inteligência, o nosso preparo, a nossa atividade e o nosso patriotismo (Id., 11/05/1935:2).

As frentenegrinas também publicaram alguns contos no jornal, mas, tal como nos artigos, não se tematizava as questões específicas das mulheres negras (Id., 05/08/1933:2; 19/08/1933:4). $\mathrm{Na}$ coleção de A Voz da Raça foram encontrados apenas 16 artigos e contos de autoria delas, alguns reforçavam a representação estereotipada da mulher negra. Em "O Cetro da Creoula", Niger traçava o perfil da "creoula". A negra seria uma mulher de "beleza sem par":

as nossas creoulas [tinham os] seus dons de beleza, a graça incomparável do seu sorriso, a que tem nos olhos toda a meiguice de uma raça $e$ nos lábios a candura imprescindível de um beijo doce, quente e sincero de mulher que sabe amar e ser amada (...). [Para completar os "elogios", escrevia Niger] A creoula é no momento que passa, destinada a ser mais conformada sentimentalista. É a mais amante, a mais constante, o seu amor é a expressão ardente de seu sentimento: - dedicação; sinceridade, grandeza de coração, amor felicidade (...) (Id., 17/03/1934:3). 
Assim, para elogiar os atributos da mulher negra, Niger reforçava o estereótipo tradicionalmente imputado a ela: uma mulher essencialmente sentimental, lasciva $e$ amante.

Às vezes, as campanhas publicitárias do jornal eram voltadas somente para as frentenegrinas:

Quereis gastar pouco e ser elegantes desde a vossa roupa branca, até o vestido ou manteaux mais fino? Quereis aprender corte e costura por um método fácil, rápido $e$ barato? Ide à Frente Negra Brasileira à Rua da Liberdade, 196. É lá que está a vossa costureira (Id., 17/03/1934:4).

Para o jornal, entretanto, o papel da mulher negra era o de esposa e "dona-de-casa". O artigo "Breviário da mulher" sanciona essa premissa, recomendando uma série de normas de conduta para a mulher conseguir um marido. A mulher não devia ser namoradeira, mas contrair relacionamentos amorosos com a perspectiva de casamento; "pecar mais por ser recatada que desenvolta, pois nada há que lhe assente tão bem como o recato, considerado por toda gente próprio do sexo". Aquelas que "andam aí pelas ruas, mostrando com excesso o que o pudor manda ocultar, (...) que se sentam em público pondo uma perna sobre a outra", deviam ser severamente censuradas. Afinal, essas mulheres

podem agradar determinados homens, mas a maioria hão de parecer pouco indicadas para mães de seus filhos, motivo por que algumas senhoritas acham noivos mas não maridos. [No final do artigo, uma advertência para as mulheres] Não esqueceis que o homem (...) costuma desejar com mais ardor justamente aquilo que menos acessivel se lhe mostra (Id., 06/1936:3).

Reconhecia-se que as normas de conduta dificultariam a conquista de um noivo, mas, quando este aparecesse, acreditava-se que se converteria em marido, fato que mais deveria interessar uma 
Participação feminina na história da luta anti-racista no Brasil

mulher. A nota "Frentenegrinas mães e filhas" - publicada na primeira página do jornal - advogava a necessidade de a mulher ser "boa dona-de-casa": "Nada mais triste, mais desolador, mais digno de lástima do que uma moça ou sra. não possuir uma educação completa, para saber ser boa dona-de-casa" (Id., 15/12/1934:1). A concepção de gênero difundida pelo jornal A Voz da Raça, de certo modo, corrobora a assertiva de Fernandes segundo a qual um estrato da população negra, nas primeiras décadas do século XX,

não só valorizava o casamento como uma "distinção social", como havia adquirido certas noções essenciais sobre as obrigações e os direitos recíprocos dos cônjuges. A mulher, principalmente, aprendera no mínimo a arrumar a casa, a cozinhar bem e a viver com o conforto possível em seu nível de pobreza (Fernandes, 1978:201). ${ }^{6}$

A partir de janeiro de 1934, o jornal passou a publicar uma coluna fixa chamada "Seção Doméstica", que, sob a coordenação de "Marister", passava receitas culinárias e, às vezes, orientações acerca dos serviços domésticos:

Com esse título [Seção Doméstica] abrimos hoje esta nova seção, por onde divulgaremos às nossas muitas e atenciosas leitoras, tudo que possam-lhes interessar da vida do lar. Toda correspondência deve ser dirigida ao signatário, nesta redação.

Sopa de batatas - Cozinha-se a precisa quantidade de batatas em água e sal. Quando cozidas passam-se por um passador, reduzindo-as a um purê e com este engrossa-se o caldo, deixa ferver em fogo lento, com os temperos necessários.

${ }^{6}$ Enfocando São Paulo na virada do século XIX para o XX, Boris Fausto (1984:58) também detectou uma "valorização na 'sociedade negra' de padrões vigentes na sociedade em geral, onde se incluem a virgindade e o casamento, se possível com todo seu envoltório formal". 
Petrônio Domingues

\begin{abstract}
Bananada - Para 1 quilo de massa de bananas cozidas e passadas em peneira, 1 quilo de açúcar. Faz-se uma calda grossa, deitam-se nela as bananas que se retiram quando estiverem moles. Mantém-se a calda ao fogo até que fique ao ponto de quebrar $e$, neste ponto, junta-se a massa, mexendo-se sempre até que tome o ponto de marmelada, juntando-se o caldo de 1 ou 2 limões ( $\mathrm{V}$ Voz da Raça. São Paulo, 06/01/1934:4).
\end{abstract}

O jornal chegou a qualificar a mulher negra de "sexo frágil". A fundação de um núcleo de mulheres negras em Jundiaí - Grupo das Rosas - foi parabenizada pelo jornal como mais uma iniciativa de "alevantamento do sexo frágil" (Id., 29/06/1935:3). Isto não aconteceu uma única vez. Ao analisar o comportamento dos homens negros em "Crônica Afeminada", Iná dizia: "eu também pertenço ao sexo fraco" (Id., 07/1936:3). Portanto, não só o jornal A Voz da Raça, mas também a própria frentenegrina qualificou a mulher negra como "sexo fraco".

Somente em sua última edição, a de número setenta, o jornal lançou uma coluna específica para atender aos anseios da mulher negra. Batizada de "Seção Feminina", a coluna não passou de seu anúncio de apresentação:

Com este número, "A Voz da Raça" inicia mais uma das suas aspirações, que é a página dedicada especialmente à mulher frentenegrina. Esperamos agora que você, amável leitora, contribua para a vitória desta iniciativa, mandando para esta redação a sua colaboração. Quando o seu trabalho não for publicado, o "Conselho da Razão" lhe dirá o porque e, isso, com o fim de estimular as pessoas de boa vontade. Certos de que todas as frentenegrinas nos honrarão com o seu trabalho, aceitem as nossas $e$ as felicitações da "A Voz da Raça" (Id., 11/1937:3). 
Participação feminina na história da luta anti-racista no Brasil

\section{À guisa de considerações finais}

A princípio, a FNB conseguiu unificar muitos grupos $e$ organizações existentes no meio negro em São Paulo. Ela foi uma das primeiras entidades a fazer a denúncia sistemática do "preconceito de cor" no país e a precursora em romper com o silêncio que pairava na opinião pública em torno das questões $e$ reivindicações dos negros no pós-abolição. Fernandes inferiu que ela realizou um trabalho de agitação, propaganda e mobilização que jamais "alcançou paralelo em outras tentativas ulteriores" (Fernandes, 1978:46).

De fato, a FNB conquistou um nível de reconhecimento sem precedentes para uma entidade negra na história do país, a ponto de alguns órgãos da sociedade civil (como a grande imprensa) e o Estado brasileiro tomarem-na como legítima representante da população negra. Seus representantes foram recebidos em audiência pelo governador do Estado de São Paulo, Armando de Salles Oliveira, e pelo presidente da República, Getúlio Vargas. Com o surgimento da FNB, "a agitação dos negros na luta pela sua dignidade humana e consciência de cidadania foi qualquer coisa de grandiosa na história da resistência" desse segmento populacional (Lucrécio, 1989:335). Nas cidades em que se instalou, a entidade representou um marco na luta anti-racista.

A atuação das mulheres negras foi imprescindível para manter a união e coesão dos associados da FNB. Em vista disso, caberia a elas parte importante do crédito pelo sucesso da entidade. Com uma postura vanguardista, as mulheres estiveram presentes em todo período de existência da FNB. Na sede central, elas criaram dois agrupamentos específicos: as Rosas Negras e a Cruzada Feminina. Em algumas delegações do interior e de outros Estados, a entidade organizou um departamento feminino. Mas não se pode ter ilusão: a FNB tinha um indubitável predomínio masculino. As mulheres ocuparam um papel que muitos interpretavam como subsidiário. Elas não assumiram, por exemplo, nenhum cargo de monta na entidade; todos os 
organismos que lhes eram reservados realizavam apenas aquelas atividades que os homens consideravam de menor relevância: as recreativas e as de assistência social.

O jornal da FNB, A Voz da Raça, deu pouco espaço para as frentenegrinas colaborarem na linha editorial. E quando estas escreviam no jornal, não costumavam pautar as questões ligadas à emancipação feminina, aliás, não havia a compreensão de que a mulher tinha problemas específicos. O jornal compartilhava da concepção de gênero que predominava na época: a mulher era um sexo frágil e devia ser preparada, fundamentalmente, para assumir seu papel de esposa, dona-de-casa e mãe, daí a existência de uma coluna fixa para veicular receitas culinárias e orientações referentes aos serviços domésticos. Ainda que concisas, as anotações deste artigo sinalizam para a necessidade de novas pesquisas acerca da história das mulheres negras no pós-Abolição, particularmente daquelas que se engajaram nos movimentos sociais do meio negro e levaram a cabo a luta anti-racista no país.

\section{Referências Bibliográficas}

ANDREWS, George Reid. Negros e brancos em São Paulo (1888 - 1988). Bauru-SP, EDUSC, 1998 [Trad.: Magda Lopes].

BACELAR, Jeferson. A Frente Negra Brasileira na Bahia. Afro-Ásia (17), Salvador, CEAO-UFBA, 1996.

BARBOSA, Márcio. (org.) Frente Negra Brasileira: depoimentos. São Paulo, Quilombhoje, 1998.

BARRos, Miguel. Discurso do representante da Frente Negra Pelotense. Estudos Afro-Brasileiros. Trabalhos apresentados ao $1^{\circ}$. Congresso Afro-Brasileiro realizado no Recife, em 1934. Fac-símile, Recife, Editora Massangana, 1988 [1935].

BASTIDE, Roger. A imprensa negra do Estado de São Paulo. Boletim de Sociologia (2), São Paulo, Faculdade de Filosofia Letras e Ciências Humanas/USP, 1951.

BICUDO, Virgínia Leone. Estudo de atitudes raciais de pretos e mulatos em São Paulo. Tese de mestrado, Escola Livre de Sociologia e Política de São Paulo, 1945. 
Participação feminina na história da luta anti-racista no Brasil

BUTLER, Kim D. Freedoms given, freedoms won: afro-brazilians in postabolition São Paulo and Salvador. New Brunswick-NJ, Rutgers University Press, 1998.

CARDoso, Paulino de Jesus Francisco. A luta contra a apatia: estudo sobre a instituição do movimento negro anti-racista na cidade de São Paulo (1915-1931). Dissertação de mestrado, História, PUC/SP, 1993.

CARDOSO, Ruth Corrêa Leite. Movimentos sociais urbanos: balanço crítico. In: SoRJ, Bernardo e ALMEIDA, Maria Hermínia Tavares de. (orgs.) Sociedade e política no Brasil pós-64. São Paulo, Brasiliense, 1983.

DiAS, Maria Odila Leite da Silva. Quotidiano e poder em São Paulo no século XIX. São Paulo, Brasiliense, 1984.

DOMINGUES, Petrônio. Uma história não contada: negro, racismo e branqueamento em São Paulo no pós-abolição. São Paulo, Ed. Senac, 2004.

Frente Negra Brasileira e a luta contra o racismo no Brasil. Revista Histórica (14), São Paulo, Arquivo do Estado de São Paulo, 2004a.

FAUSTO, Boris. Crime e cotidiano: a criminalidade em São Paulo (18801924). São Paulo, Brasiliense, 1984.

FeLIX, Marcelino. As práticas político-pedagógicas da Frente Negra Brasileira na cidade de São Paulo (1931-1937). Dissertação de mestrado, Educação, PUC/SP, 2001.

FERNANDES, Florestan. A integração do negro na sociedade de classes. $3^{\mathrm{a}}$ ed. São Paulo, Ática, 1978.

FERRARA, Miriam Nicolau. A imprensa negra paulista (1915-1963). São Paulo, Ed. FFLCH-USP, Coleção Antropologia, nº 13,1986.

FURTADO, Júnia Ferreira. Chica da Silva e o contratador dos diamantes: o outro lado do mito. São Paulo, Companhia das Letras, 2003.

GIACOMINI, Sonia Maria. Mulher e escrava; uma introdução histórica ao estudo da mulher negra no Brasil. Petrópolis-RJ, Vozes, 1988.

GRAHAM, Sandra Lauderdale. Caetana diz não: histórias de mulheres da sociedade escravista brasileira. São Paulo, Companhia das Letras, 2005 [Trad.: Pedro Maia Soares]. 
GRINBURG, Keila. Liberata. A lei da ambigüidade. Rio de Janeiro, Relume Dumará, 1994.

LEITE, José Correia e MoREIRA, Renato Jardim. Movimentos sociais no meio negro. São Paulo, mimeo., s/d.

LUCRÉCIO, Francisco. Memória histórica: a Frente Negra Brasileira. Revista de Cultura Vozes (83), Petrópolis-RJ, 1989.

MAUÉS, Maria Angélica Motta. Negro sobre negro: a questão racial no pensamento das elites negras brasileiras. Tese de Doutorado, Sociologia, IUPERJ, 1997.

MiTCHELL, Michael. Racial consciousness and the political attitudes and behavior of blacks in São Paulo, Brazil. Dissertação de Ph.D., Ciência Política, Universidade de Indiana, 1977.

MotT, Luiz. Uma escrava no Piauí escreve uma carta. Mensário do Arquivo Nacional (5), Rio de Janeiro, 1979.

Rosa Egipcíaca; uma santa africana no Brasil. Rio de Janeiro, Bertrand Brasil, 1993.

MOTT, Maria Lúcia de Barros. Submissão e resistência; a mulher escrava na luta contra a escravidão. São Paulo, Contexto, 1988.

MourA, Clóvis. Organizações negras. In: SINGER, Paulo e BRANT, Vinícius. (orgs.) São Paulo: o povo em movimento. Petrópolis, Vozes/ CEBRAP, 1980, pp.143-175.

OliveIRA, Laiana de. A Frente Negra Brasileira: política e questão racial nos anos 1930. Dissertação de mestrado, História, UERJ, 2002.

PAIVA, Eduardo França. Celebrando a alforria: amuletos e práticas culturais entre as mulheres negras e mestiças do Brasil. In: KANTOR, Iris e JANCSÓ, István. (orgs.) Festa: cultura e sociabilidade na América Portuguesa. Vol. II. São Paulo, Hucitec/Edusp/Imprensa Oficial, 2001, pp.505-518.

PINTO, Regina Pahim. O movimento negro em São Paulo: luta e identidade. Tese de doutorado, Antropologia, USP, 1993.

RAmos, Artur. O espírito associativo do negro brasileiro. Revista do Arquivo Municipal de São Paulo (47), São Paulo, 1938, pp.105-126.

SANTOS, José Antônio dos. Raiou a Alvorada: Intelectuais negros e imprensa, Pelotas (1907-1957). Pelotas-RS, Ed. Universitária, 2003. 
Participação feminina na história da luta anti-racista no Brasil

SILVA, José Carlos Gomes da. Os sub urbanos e a outra face da cidade. Negros em São Paulo: cotidiano, lazer e cidadania (1900-1930). Dissertação de mestrado, Antropologia, Unicamp, 1990.

SILVA, Maria Aparecida Pinto. A Voz da Raça: uma expressão negra no Brasil que queria ser branco. Tese de doutorado, Antropologia, PUC/SP, 2003.

SOARES, Cecilia Moreira. As ganhadeiras: mulher e resistência negra em Salvador no século XIX. Afro-Ásia (17), Salvador, CEAO-UFBA, 1996, pp.57-71. 